\title{
To Establish A Normal Range of Inter-Incisal Opening - A Study of 756 Subjects of Age Group 20-50 Years in Yamunanagar City, Haryana.
}

\author{
Aruna Vijay Singh ${ }^{1}$ \\ Nymphea Pandit ${ }^{2}$
}

\author{
Dr. Monica Sharma ${ }^{3}$
}

\section{ABSTRACT}

Aim- 1.The aim of this study was to investigate the average maximum range of inter-incisal mouth opening in a representative sample of the adult subjects of Haryana. 2. To see any correlation between maximal inter-incisal opening with age.

Methods- Maximum mouth opening was studied in 756 adult subjects with age range of 20-50 years in Yamunanagar, Haryana. Age limit was further divided into three groups (20-30, 31-40, 41-50). Those with clinical history of TMJ involvement, OSMF, any trauma, odontogenic and non-odontogenic infections, dental prosthesis on the anterior teeth, congenital anomalies in the maxillofacial region were excluded from this study. The measurements were recorded twice and mean of the two values were taken.

Statistical Analysis- Independent sample t-test was calculated to compare age and mouth opening in both male and females respectively. Bivariate pearson correlation was used to see any relationship between age and mouth opening. P-value $\leq 0.05$ and $\mathrm{CI}$ (confidence interval) at 95\% were considered statistically significant.

The Results-The average mouth opening of males $(45.36 \pm 6.70 \mathrm{~mm})$ subjects was higher as compared to female $(41.27 \pm 6.75 \mathrm{~mm})$ with significant, p-value 0.000 . The mean mouth opening \pm SD for both sexes combined was $43.39 \pm 7.02 \mathrm{~mm}$. The corresponding values for mean inter-incisal opening in male population aged 20-30, 31-40, 41-50 were 45.52 $\pm 7.15,46.16 \pm 5.47,42.96 \pm 6.82 \mathrm{~mm}$ and in female population aged $20-30,31-40,41-50$ were $41.40 \pm 7.08,41.60 \pm 6.29$ and $40.03 \pm 6.38 \mathrm{~mm}$ respectively.

Conclusion- Maximal mouth opening differ significantly with gender. There is a decrease in MMO with older age group.

Key words: Maximum mouth opening, Range of motion, Temporomandibular joint disorders (TMD), Oral Sub Mucous Fibrosis (OSMF).

\section{INTRODUCTION:}

Mouth opening assessment is an important part of every clinical examination in dentistry. However, few studies of the normal range of maximal mouth opening have been undertaken in different ethnic group of Indian population. With limited availability of data on normal range of mouth opening, there remain a gap in clinical examination of patients particularly with Temperomandibular disorder (TMD), (Oral Submucous Disorder) and with dysfunction of other masticatory disorder.

The greatest distance between the incisal edge of the maxillary central incisors to the incisal edge of the mandibular central incisors at the midline when the mouth is open as wide as possible is defined as the interincisal opening ${ }^{1}$.

One of the important factor in determining the function of the temporomandibular joint (TMJ) and the masticatory muscle status is the jaw opening capacity ${ }^{2}$. Therefore the range of mandibular movement is a valuable measure in the diagnosis of patients with suspected functional disorders of the masticatory apparatus ${ }^{3}$.

Restricted mouth opening may occur due to intra or extracupsular pathology of TMJ ${ }^{4,5,6,7}$, head and neck cancer patients $^{8,10,11}$, iatrogenic causes such as third molar extractions, hematomas secondary to dental infection and delayed effect of intermaxillary fixation after mandibular fracture or other trauma ${ }^{12}$.

\section{AIM OF THE STUDY}

1. To determine the maximum normal mouth opening in the studied population so as to establish a normal range of mobility which can useful as an indicator of the function of TMJ and the masticatory system.

2. To investigate any correlation between age and Maximum mouth opening (MMO) both in male and female.

\section{METHODOLOGY}

Over a period of 10-month, a survey was undertaken at the concerned hospital to estimate the maximal inter-incisal opening of normal adult population. The proposed study included 756 patients ( 392 male and 364 female) which were randomly selected from concerned hospital. Patients was divided further into three age groups - 20-30, 31-40, 41-50.

Consent was taken from the ethical committee and all the participants were informed about the objective and the purpose before conducting the study. Those patients who had no history of TMD, had functional occlusion with no

1. Prof and Head, Dept. of Oral Medicine and Radiology, 2. Prof. and Head, Dept. of Periodontics,

3. Reader, Dept. of Oral Medicine and Radiology, DAV Dental College and Hospital, Yamunanagar, Haryana 135001 
extrusive interferences and had intact dentition were included in the study. Patients that were excluded from the study were those with a history of -

Temporomandibular dysfunction.

\section{Trauma.}

Bruxism.

Patients with anterior teeth missing (central incisors) / dental prosthesis.

Any acute odontogenic and non-ondontogenic infections associated with pain/burning sensation

\section{Congenital facial anomaly}

Patients with oral submucous fibrosis.

The information was collected through questionnaire given to the patients. Selections of the subjects for the study were finalized after reviewing of the questionnaire by the experts. A through intra oral, extra oral and TMJ examination was done and the inter-incisal opening was measured by using geometric divider and millimeter ruler as a study instrument. Each patients was seated comfortable on a dental chair and was asked to open the mouth as wide as possible. The maximum distance was measured from the incisal edge of the maxillary central incisors to the incisal edge of the mandibular central incisors at the midline. The value was measured in millimeters. The examination and the measurement were performed by a single examiner to avoid any bias in the study.

\section{STATISTICAL ANALYSIS}

Linear measurements of quantitative data like age (years) and mouth opening $(\mathrm{mm})$ are presented in mean \pm SD along its maximum and minimum values. Independent sample ttest was calculated to observe any significant differences in mouth opening in both male and females respectively. Bivariate pearson correlation was used to see any relationship between age and mouth opening. P-value $\leq$ 0.05 and CI (confidence interval) at $95 \%$ were considered statistically significant.

\section{THE RESULTS}

Out of the 756 patients ( 392 male and 364 female), mean ages of all subjects was $31.53 \pm 7.95$, with age range $20-50$ years. Moreover, the mean age \pm SD for both male and female subject were $31.07 \pm 7.67$ and $32.04 \pm 8.26$ respectively. The mean inter-incisal opening \pm SD for both sexes combined was $43.39 \pm 7.02 \mathrm{~mm}$. The mean interincisal opening of males $(45.36 \pm 6.70 \mathrm{~mm})$ subjects was higher as compared to female $(41.27 \pm 6.75 \mathrm{~mm})$ with significant, p-value 0.000 .
The corresponding values for mean inter-incisal opening in male population aged 20-30, 31-40, 41-50 were $45.52 \pm 7.15,46.16 \pm 5.47,42.96 \pm 6.82 \mathrm{~mm}$ and in female population aged $20-30,31-40,41-50$ were $41.40 \pm$ $7.08,41.60 \pm 6.29$ and $40.03 \pm 6.38 \mathrm{~mm}$ respectively.

The maximumal inter-incisal opening was highly significant and negatively correlated with age; this indicates that there is decrease in mouth opening with increasing age ( $\mathrm{r}=-0.121$ with $\mathrm{p}$-value as 0.000 , less than 0.01 ). Similarly, in male and female population ages was significantly negative correlation with mouth opening $(r=-0.114$ with $\mathrm{p}$ value $=0.024)$ in male and in female an insignificant moderate negative correlation $(\mathrm{r}=-0.102$ with $\mathrm{p}=0.052)$ were observed.

\section{DISCUSSION}

A high frequency of limited mouth opening is observed in dental clinical practice. However, few studies of normal range of mouth opening have been undertaken in Indian population. The normal range of mouth opening in different geographical or ethnic variation seems to be overlooked.

Maximum mouth opening were observed in males than females. This may be because the mouth opening depends upon the size of the mandible which is greater in males than female as done in a study by Scavone $\mathrm{H}$ et al (2006) ${ }^{13}$. Measurements of maximal mouth opening may vary from $40-77 \mathrm{~mm}$ in male and $32-75 \mathrm{~mm}$ in female subjects.

A difference in mouth opening among genders has been reported with man having tendency to open on average five $\mathrm{mm}$ more than women ${ }^{14}$. Similar results was observed in this study with man having tendency to open more with an average $45.36 \mathrm{~mm}$ (range 52.06-38.66) as compared to female $41.27 \mathrm{~mm}$ (range 48.02-34.52).

In this present study maximal inter-incisal opening decreases significantly with ageing in both male and female. This findings agrees with the findings done by Aqibsohail and Amjad A (2011) in Pakistani population ${ }^{15}$, Gallagher et al (2004) in Irish population ${ }^{16}$ and yao KT and Lin C (2009) in Chinese population ${ }^{17}$. This may be due to changes in TMJ as a part of normal ageing process. To meet the functional demand, condylar remodeling, a physiological process occurs to adapt the structure of the temperomandibular joints (TMJ). In a study done by Mathew AN , 2011, an statistically significant increase in radiographic changes in condylar morphology was observed with increase in age ${ }^{18}$.

Among the three age groups $(20-30,30-40,40-500)$ highest inter-incisal opening was observed in middle age 
group (30-40) and lowest inter-incisal opening in older age group (40-50). Similarly, in a study by Mezitis $M$ et al in Greek population, aged 18-70, greatest mouth opening was recorded in younger age group (18-30) both in male (56.6 $\mathrm{mm})$ and female $(51.0 \mathrm{~mm})$. The lowest measurements were in older age group 51-60 years in male $(51.0 \mathrm{~mm})$ and $61-70$ years in female $(44.5 \mathrm{~mm})^{19}$.

Majority of studies had demonstrated changes in mouth opening with age and gender. However, variation in changes is due to ageing remain unclear. Further survey should be perform in larger sample size in different regions of Indian population.

\section{CONCLUSION}

Within the limits of this study, we conclude the following points-

1. MMO differ significantly with gender.

2. There is a decrease in MMO with older age group.

This results agrees with the studies reported in different countries.

\section{REFERENCES}

1. Placko G, Bellot-Samson V, Brunet $\mathrm{S}$ et al. Normal mouth opening in the adult French population . Rev stomatol Chir Maxillofac 2005;106(5):267-71.

2. Fanghanel J, Gedrange T. On the development, morphology and function of the temporomandibular joint in the light of the orofacial system. Ann. Anat.2007;189(4):314-319.

3. Fanghanel J, Gedrange $T$. The facephysiognomic expressiveness and human identity. Ann. Anat.2006;188(3);261-266.

4. Fasano CJ, Chudnofsky C, Vanderbek P. Bilateral peritonsillar abscess: not your usual sore throat. J Emerg Med 2005;31(2):110-16.

5. Al Belasy FA: Ultrasound-guided drainage of submassetric space abscesses. J oral Maxillofac Surg 2005;63:36-41.

6. Yano H, Yamamoto H, Hirata R et al. Post-traumatic severe trismus caused by impairement of the masticatory muscle. $\mathrm{J}$ Craniofac Surg 2006;16:277-80.
8. Ortakoglu K, Akcam T, Sencimen M et al. Osteochondroma of the mandible causing severe facial asymmetry: a case report. Oral surg Oral Med Oral Pathol Oral Radiol Endod 2007;103:21-28.

9. De Sousa LM, Nagamine HM, Chaves TC, Grossi DB, Regall $\mathrm{SCH}$, De Oliviera AS. Evyalation of mandibular range of motion in Brazilian children and its correlation to age, height, weight and gender. Braz Oral Res 2008;22:61-66.

10. Dijkstra PU, Sterken MW, Pater R, Spijkervet FKL, Roodenburg JLN. Exercise therapy for trismus in head and neck cancer. Oral Oncol 2007;43:389-94.

11. Molen L, van Rossum MA, Burkhead LM, Smeele LE, Hilgers FJ: functional outcomes and rehabilation strategies in patients treated with chemoradiotherapy for advanced head and neck cancer: a systemic review. Eur arch Otorhinolaryngol 2009, 266:901-02.

12. Rahim AU, Warraich RA, Ishfar M, wahid A. pattern of mandibular fractures at Mayo hospital, Lahofe. Pak Oral Dent J 2006;26:239-42.

13. Scavone H, Trevisan H, Garib DG, Ferreira FV. Facial profile evaluation in Japanese-Brazilian adults with normal occlusion and well-balanced faces. Am J Orthod Dentofacial Orthop. 2006;129(6):721-25.

14. Cortese SG, Oliver LM, Biondi AM: Determination of range of mandibular movements in adults without temperomandibular disorders. J Craniomandib Pratt 2007;25:200-205.

15. Aqibsohail, Aneela Amjad. The range of inter-incisal opening among university students of Ajman, UAE. Pak Oral \& Dental Jour. 2011;31(1):37-41.

16. Gallagher C, Gallagher V, Whelton $\mathrm{H}$ and Croin $\mathrm{M}$. The normal range of mouth opening in an Irish population. Journal of oral Rehabilation .2004;31(10):110-116.

17. Kuang-Ta Yao, Chia-Cheng Lin, Chao-Ho Hung. Maximum mouth opening of ethnic Chinese in Taiwan. Jour Dental Sciences.2009;4(1):40-44.

18. Anuna Laila Mathew, Amar A.Sholapurkar and Keerthilatha M. Pai. Condylar Changes and Its association with Age, TMD, and Dentition Status: A Cros-sectional Study. Intern Jour of Dent. 2011;2011(2011): 7 pages

19. Mezitis M, Rallis G, Zachariades N. The normal range of mouth opening. J oral Maxillofac Surg 1989;47:1028-1029. 